\title{
Gallic acid inhibits migration and invasion of SCC-4 human oral cancer cells through actions of NF-кB, Ras and matrix metalloproteinase-2 and -9
}

\author{
CHAO-LIN KUO ${ }^{1}$, KUANG-CHI LAI ${ }^{2,3}$, YI-SHIH MA ${ }^{4,5}$, SHU-WEN WENG ${ }^{6}$, \\ JING-PIN $\mathrm{LIN}^{7}$ and JING-GUNG CHUNG ${ }^{8,9}$
}

\begin{abstract}
Departments of ${ }^{1}$ Chinese Pharmaceutical Sciences and Chinese Medicine Resources, ${ }^{2}$ Medicine, China Medical University, Taichung; ${ }^{3}$ Department of Surgery, China Medical University Beigang Hospital, Yunlin; ${ }^{4}$ School of Chinese Medicine for Post-Baccalaureate, I-Shou University, Kaohsiung; ${ }^{5}$ Department of Chinese Medicine, E-Da Hospital, Kaohsiung;

${ }^{6}$ Graduate Institute of Chinese Medicine, China Medical University, Taichung; ${ }^{7}$ School of Chinese Medicine, China Medical University, Taichung; ${ }^{8}$ Department of Biological Science and Technology, China Medical University, Taichung; ${ }^{9}$ Department of Biotechnology, Asia University, Wufeng, Taichung, Taiwan, R.O.C.
\end{abstract}

Received February 8, 2014; Accepted April 29, 2014

DOI: $10.3892 /$ or.2014.3209

\begin{abstract}
Oral cancer is one of the major causes of mortality in humans and squamous cell carcinoma is the most common type of oral cancer. Gallic acid (GA) is a natural product that induces cell death through cell cycle arrest and induction of apoptosis. There is no available information on whether GA affects cell migration and invasion of human oral cancer cells. We determined if GA inhibited migration and invasion of SCC-4 (human squamous cell carcinoma) human oral cancer cells. GA significantly inhibited migration and invasion of SCC- 4 cells based on results from the wound healing assay and Matrigel Cell Migration Assay and Invasion System. We also showed that GA significantly inhibited matrix metalloproteinase (MMP)-2 and MMP-9 activity. GA reduced protein levels of FAK, MEKK3, p-PERK, p-p38, p-JNK1/2,p-ERK1/2, SOS1, RhoA, Ras, PKC, p-AKT(Thr308), PI3K, NF-кB p65, MMP-2 and MMP-9 in SCC-4 cells. Translocation of NF- $\kappa$ B and RhoA from the cytosol to the nucleus was reduced by GA in SCC-4 cells. In summary, GA inhibits migration and invasion of SCC-4 cells by inhibiting NF- $\kappa \mathrm{B}$ expression causing suppression of MMP-2 and MMP-9 activity. GA may have potential as a therapeutic agent for the treatment of oral cancer.
\end{abstract}

Correspondence to: Professor Jing-Gung Chung, Department of Biological Science and Technology, China Medical University, 91 Hsueh-Shih, Taichung 404, Taiwan, R.O.C.

E-mail: jgchung@mail.cmu.edu.tw

Professor Jing-Pin Lin, School of Chinese Medicine, China Medical University, Taichung 404, Taiwan, R.O.C.

E-mail: jplin@mail.cmu.edu.tw

Key words: gallic acid, migration, invasion, SCC-4 human oral cancer cells, NF-kB

\section{Introduction}

Squamous cell carcinoma (SCC) accounts for $\sim 90 \%$ of oral cancers (1); it is the sixth most common malignancy in the world (2) and one of the leading causes of cancer-related mortality $(3,4)$. In Taiwan, based on a 2012 report from the Department of Health, R.O.C. (Taiwan), 11.0 individuals per 10,000 die annually from oral cancer. In Taiwan, oral cancer is the fourth most common cancer in men and the 16th in women. There are several different treatments for oral cancer (including surgery, radiation and chemotherapy); however, the overall survival rate is unsatisfactory (4). A challenge to cancer treatment is that cancer cells migrate to and invade other tissues or organs. There is a need to find new agents to treat SCC.

Gallic acid (3,4,5-trihydroxybenzoic acid; GA) exists in natural plants and has been shown to have anticancer effects in human leukemia HL-60RG (5), lung cancer (6), stomach cancer, colon cancer $(7)$, prostate cancer $(8,9)$, melanoma $(10)$ and esophageal cancer (11), PC12 rat pheochromocytoma (12) and mouse leukemia WEHI-3 cells (13). Our laboratory previously reported that GA induces apoptosis in human lung cancer NCI-H460 cells in vitro and in vivo (14). Cancer metastasis is caused by cell adhesion, migration and invasion. GA has anti-metastatic effects on gastric cancer cells which is due to inhibition of $\mathrm{NF}-\kappa \mathrm{B}$ activity and downregulation of PI3K/ AKT/small GTPs signaling (15). GA inhibits the migration and invasion of A375.S2 human melanoma cells through the inhibition of matrix metalloproteinase (MMP)-2 and Ras (16), and GA inhibits adhesion of melanoma B16F10 cells (14). Recently, we also found that GA-inhibited migration and invasion in U-2 OS cells that may be due to downregulation of PKC, inhibition of mitogen-activated protein kinase (MAPK) and PI3K/AKT, resulting in inhibition of MMP-2 and MMP-9 expression (17). There are no reports on whether GA blocks migration and invasion of human oral cancer cells. In the present study, we determined whether GA inhibits migration and invasion of human oral cancer SCC-4 cells in vitro. 


\section{Materials and methods}

Materials and chemicals. GA, dimethyl sulfoxide (DMSO), pyruvate, penicillin $\mathrm{G}$, streptomycin, trypan blue and Triton X-100 were purchased from Sigma Chemical. (St. Louis, MO, USA). Primary and secondary antibodies for western blotting were purchased from Biotechnology (Santa Cruz, CA, USA). Materials and chemicals for electrophoresis were obtained from Bio-Rad (Hercules, CA, USA).

SCC-4 cell culture. The SCC-4 human oral cell line was purchased from the Food Industry Research and Development Institute (Hsinchu, Taiwan). Cells were cultured in $90 \%$ DMEM medium with $10 \%$ FBS and $2 \mathrm{mM}$ L-glutamine containing antibiotics $(100 \mathrm{U} / \mathrm{ml}$ penicillin and $100 \mu \mathrm{g} / \mathrm{ml}$ streptomycin). Cells were cultured in $75-\mathrm{cm}^{2}$ tissue culture flasks and incubated under a humidified $5 \% \mathrm{CO}_{2}$ atmosphere at $37^{\circ} \mathrm{C}$ as previously described (18).

Cell viability assay. SCC- 4 cells $\left(2 \times 10^{5}\right.$ cells/well) were maintained in 12-well plates for $24 \mathrm{~h}$. Cells were then incubated with $0,5,30$ and $60 \mu \mathrm{M}$ of GA for 24 and $48 \mathrm{~h}$. Each treatment was performed in triplicate. Cells were harvested and PI $(5 \mu \mathrm{g} / \mathrm{ml})$ added to the cells and analyzed using a PI exclusion method by flow cytometry (BD Biosciences, FACSCalibur, San Jose, CA, USA) as previously described $(18,19)$.

Cell-matrix adhesion assay. SCC- 4 cells $\left(2 \times 10^{5}\right.$ cells/well) were maintained in 12-well plates and were then incubated with 0,5 , 30 and $60 \mu \mathrm{M}$ of GA for 24 and $48 \mathrm{~h}$. Cells were then placed on 24-well plates which were coated with $150 \mu \mathrm{l}$ of $10 \mu \mathrm{g} / \mathrm{ml}$ type I collagen for $2 \mathrm{~h}$. Non-adherent cells were removed and adherent cells were fixed with ethanol for $15 \mathrm{~min}$ and then stained with $0.2 \%$ crystal violet for $10 \mathrm{~min}$ and washed with PBS. Cells were lysed in $0.2 \%$ Triton X-100 for $30 \mathrm{~min}$ and $150 \mu \mathrm{l}$ of the lysate was added to a 96-well ELISA plate. The absorbance (540 nm) was measured as described previously (19).

Wound healing assay. SCC- 4 cells $\left(5 \times 10^{5}\right.$ cells/well) were kept in 10-cm Petri dishes for $24 \mathrm{~h}$. Wounds were created with a sterile yellow micropipette tip on cell monolayers. Unscraped cells were washed with PBS three times and dead cells removed and fresh DMEM medium supplemented with FBS containing $0,5,30$ and $60 \mu \mathrm{M}$ of GA added for $24 \mathrm{~h}$. The wound healing area was then examined and images were captured using an inverted microscope as described previously $(18,19)$.

Cell migration and invasion assays. Matrigel Cell Migration Assay and Invasion System were used for measuring cell migration and invasion, respectively, as described previously (18). The cell migration assay was performed using Transwell cell culture chambers (8-mm pore size; Millipore, Billerica, MA, USA). SCC- 4 cells $\left(5 \times 10^{4}\right.$ cells/well $)$ were added to serumfree DMEM medium and placed in the upper chamber of the Transwell insert and incubated with 0,30 and $60 \mu \mathrm{M}$ of GA. DMEM medium (90\%) containing $10 \%$ FBS was added to the lower chamber as a chemoattractant. Following incubation for 24 and $48 \mathrm{~h}$, non-migrating cells were removed from the top chamber with a cotton swab. The cells on the lower surface were fixed with $4 \%$ formaldehyde in PBS. At the end of fixation, the chambers were rinsed with PBS and cells in the lower chamber were stained with $2 \%$ crystal violet in $2 \%$ ethanol for $10 \mathrm{~min}$. Images were counted and captured using a light microscope at $\mathrm{x} 200$. The cell invasion assay was performed the same as the cell migration assay except that the filter membrane was coated with Matrigel from a BioCoat Matrigel invasion kit. Cells that invaded to the underside of the filter were counted using a light microscope at x200 as described previously $(18,19)$.

Gelatin gel zymographic assay for MMP-2 activity. Gelatin gel zymography was used to quantify MMP-2 activity according to the manufacturer's instructions. Briefly, SCC-4 cells $\left(5 \times 10^{5}\right.$ cells/well) were maintained in 12 -well plates and then treated with GA $(0,5,30$ and $60 \mu \mathrm{M})$ for 24 and $48 \mathrm{~h}$. Total protein $(50 \mu \mathrm{g})$ was re-suspended in non-reducing loading buffer and incubated at $37^{\circ} \mathrm{C}$ for $15 \mathrm{~min}$. Electrophoresis was performed on $10 \%$ SDS-PAGE cast with $0.1 \%$ gelatin and electrophoresed on Novex ${ }^{\circledR}$ Zymogram gels (Life Technologies). The specific MMP-2 bands were detected by staining with Coomassie Brilliant Blue (Life Technologies) as described previously $(18,19)$.

Western blot analysis of proteins associated with cell migration and invasion. SCC- 4 cells $\left(1 \times 10^{6}\right.$ cells/well) were placed in 6-well plates for $24 \mathrm{~h}$ and were then incubated with $0,5,30$ and $60 \mu \mathrm{M}$ of GA for 0,24 and $48 \mathrm{~h}$. Cells were harvested, lysed, and total protein determined by a Bio-Rad protein assay kit (Hercules, CA, USA) with bovine serum albumin (BSA) as the standard as described previously $(18,19)$. Samples $(30 \mu \mathrm{g}$ protein) were loaded onto $12 \%$ SDS-polyacrylamide gels, electrophoresed and then electrotransferred to nitrocellulose membranes, blotted with the relevant primary antibodies [antiFAK, MEKK3, p-PERK, p-p38, p-JNK1/2, p-ERK1/2, SOS1, RhoA, GRB2, Ras, PKC, p-AKT (Thr308), PI3K, NF-кB p65, MMP-2 and MMP-9], washed, and then stained with a secondary antibody. Protein bands were examined by an enhanced chemiluminescence reagent (ECLTM; Amersham Biosciences) and bands were quantified using an NIH Image analyzer (NIH, Bethesda, MD, USA) as described previously $(18,19)$.

Immunofluorescence staining and confocal laser scanning microscopy. SCC- 4 cells $\left(3 \times 10^{5}\right.$ cells/well) were plated on 6-well chamber slides, treated with 0,30 and $60 \mu \mathrm{M}$ of GA for $24 \mathrm{~h}$, and fixed with formaldehyde (3\%) in PBS for $15 \mathrm{~min}$. The cells were permeabilized using $0.1 \%$ Triton X-100 in PBS for $1 \mathrm{~h}$ and washed three times with PBS followed by blocking of SCC- 4 cells $\left(3 \times 10^{5}\right.$ cells/well) using $2 \%$ BSA in nonspecific binding sites as described previously (18). Cells were stained with primary antibodies such as anti-NF- $\mathrm{kB}$ p65 and RhoA (1:100 dilution) overnight, and were then stained with secondary FITC-conjugated goat anti-mouse IgG (1:200 dilution) (green fluorescence). Cell nuclei were counterstained with PI (Molecular Probes; Invitrogen Corp.) (red fluorescence). All samples were photomicrographed using a Leica TCS SP2 confocal spectral microscope as described previously $(18,19)$.

Statistical analysis. All experiments were performed in triplicate and data are expressed as mean \pm SD. Statistical analysis was carried out using Student's t-test, with values of ${ }^{*} \mathrm{P}<0.05$ considered to indicate statistically significant differences. 


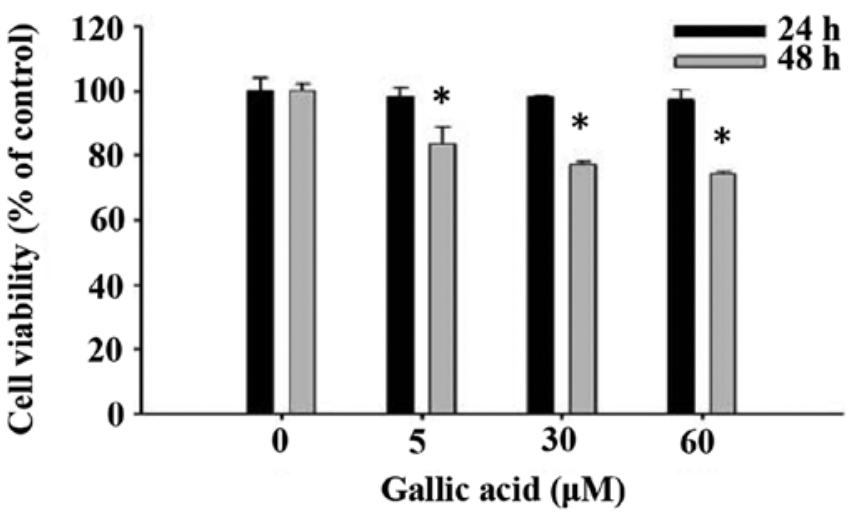

Figure 1. Gallic acid (GA) decreases the percentage of viable SCC-4 human oral cancer cells. Cells $\left(2 \times 10^{5}\right.$ cells/well) were incubated with $0,5,30$ and $60 \mu \mathrm{M}$ of GA for 24 and $48 \mathrm{~h}$ and were then harvested for measuring the percentage of viable cells by flow cytometry as described in Materials and methods. ${ }^{*} \mathrm{P}<0.05$, significant difference between GA-treated and control groups as analyzed by Student's t-test.

\section{Results}

$G A$ decreases the percentage of viable SCC-4 human oral cancer cells. We evaluated the effects of GA on cell viability using flow cytometry and results are shown in Fig. 1. GA at concentrations of 5-60 $\mu \mathrm{M}$ significantly reduced cell viability in a dose and time-dependent manner (Fig. 1).

GA inhibits the adhesion of SCC-4 cells in vitro. SCC- 4 cells were treated with $0,5,30$ and $60 \mu \mathrm{M}$ GA and inhibition of cell adhesion was determined using an ELISA reader. Results are shown in Fig. 2A and B. Cell adhesion was significantly reduced dose- and time-independently by GA compared with control groups.

GA suppresses the migration of SCC-4 cells in vitro. SCC-4 cells were treated with $0,5,30$ and $60 \mu \mathrm{M}$ of GA and wound healing assay performed. Data in Fig. 3 show that GA inhibited the migration of SCC- 4 cells based on the extent of wound closure. These effects were dose- and time-dependent.

$G A$ inhibits the migration and invasion of SCC-4 cells in vitro. Cell migration activity and invasion potential of SCC-4 cells were examined and photographed and the representative figures and evaluated inhibitions are shown in Fig. 4. Fig. 4A and $\mathrm{B}$ indicate that GA significantly inhibited migration of SCC- 4 cells, ratio of migrated cells went from 50.56 to $36.81 \%$ treated with 30 and $60 \mu \mathrm{M}$ respectively at $24 \mathrm{~h}$, to 66.40 and $51.99 \%$ at 48 h. This was in agreement with results from the healing assay (Fig. 3). Fig. 4C and D indicate that GA significantly inhibited the invasion of SCC-4 cells, ratio of invaded cells went from 53.18 to $40.17 \%$ treated with 30 and $60 \mu \mathrm{M}$ respectively at $24 \mathrm{~h}$, to 65.67 and $54.74 \%$ at $48 \mathrm{~h}$.

GA inhibits MMP-2 activity of SCC-4 cells. Effects of GA on MMP-2 activity were determined using gelatin zymography. As shown in Fig. 5, SCC-4 cells constitutively secreted high levels of MMP-2 but when incubated with GA at 5, 30 and $60 \mu \mathrm{M}$ for 24 and $48 \mathrm{~h}, \mathrm{MMP}-2$ activity was significantly reduced. This effect of GA was dose-dependent (Fig. 5).
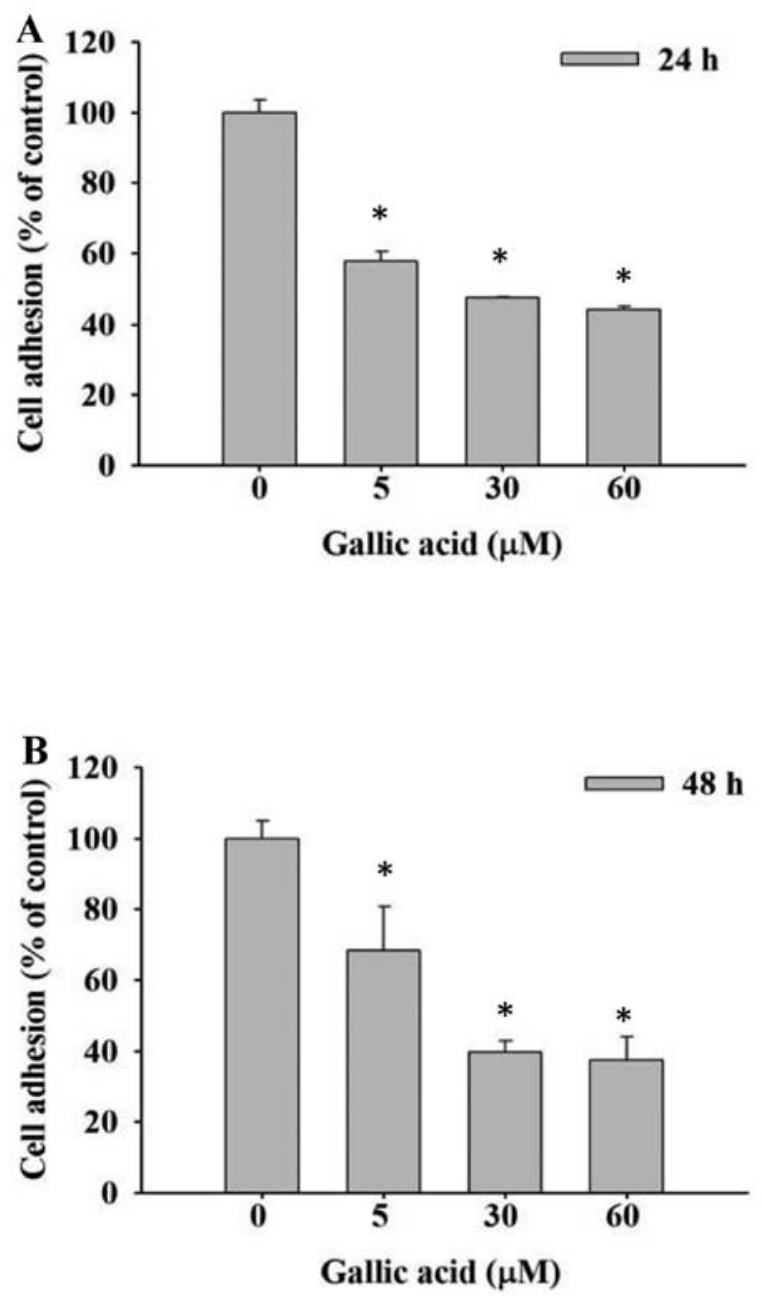

Figure 2. Gallic acid (GA) inhibits the cell-matrix adhesion of SCC-4 cells SCC- 4 cells $\left(2 \times 10^{5}\right.$ cells/well) were incubated with $0,5,30$ and $60 \mu \mathrm{M}$ of GA for (A) 24 and (B) $48 \mathrm{~h}$. All cells were placed on 24-well plates which were coated with $150 \mu \mathrm{l}$ of type I collagen for $2 \mathrm{~h}$. Then adherent cells were fixed with ethanol for $15 \mathrm{~min}$ and were stained with $0.2 \%$ crystal violet for $10 \mathrm{~min}$. Cells were lysed in $0.2 \%$ Triton X-100 for $30 \mathrm{~min}$ and the $150 \mu 1$ lysed solution was individually added to a 96-well ELISA plate, followed by measurement of the $540 \mathrm{~nm}$ absorbance as described in Materials and methods. ${ }^{*} \mathrm{P}<0.05$, significant difference between GA-treated and control groups as analyzed by Student's t-test.

GA alters levels of proteins associated with migration and invasion of SCC- 4 cells. MMP-2 and MMP-9 are potential target molecules for anti-metastatic activity, and we investigated the effects of GA on MMP-2 and MMP-9 and associated signal protein levels in SCC-4 cells. GA markedly reduced protein levels of FAK, MEKK3, p-PERK (Fig. 6A), p-p38, p-JNK1/2, p-ERK1/2 (Fig. 6B) and SOS1, RhoA, Ras (Fig. 6C). It was also observed that protein levels of PKC, p-AKT (Thr308), PI3K, (Fig. 6D) were decreased in GA-treated cells compared with control cells.

GA alters translocation of $N F-\kappa B$ and RhoA in SCC-4 cells. Effects of GA on distribution of NF- $\kappa$ B p65 and RhoA in SCC-4 cells were examined by confocal laser system microscopy and results can be seen in Fig. 7A and B. GA inhibited the NF- $\kappa \mathrm{B}$ p65 (Fig. 7A) and RhoA (Fig. 7B) protein levels in cytosol but increased the protein levels in nuclei. 

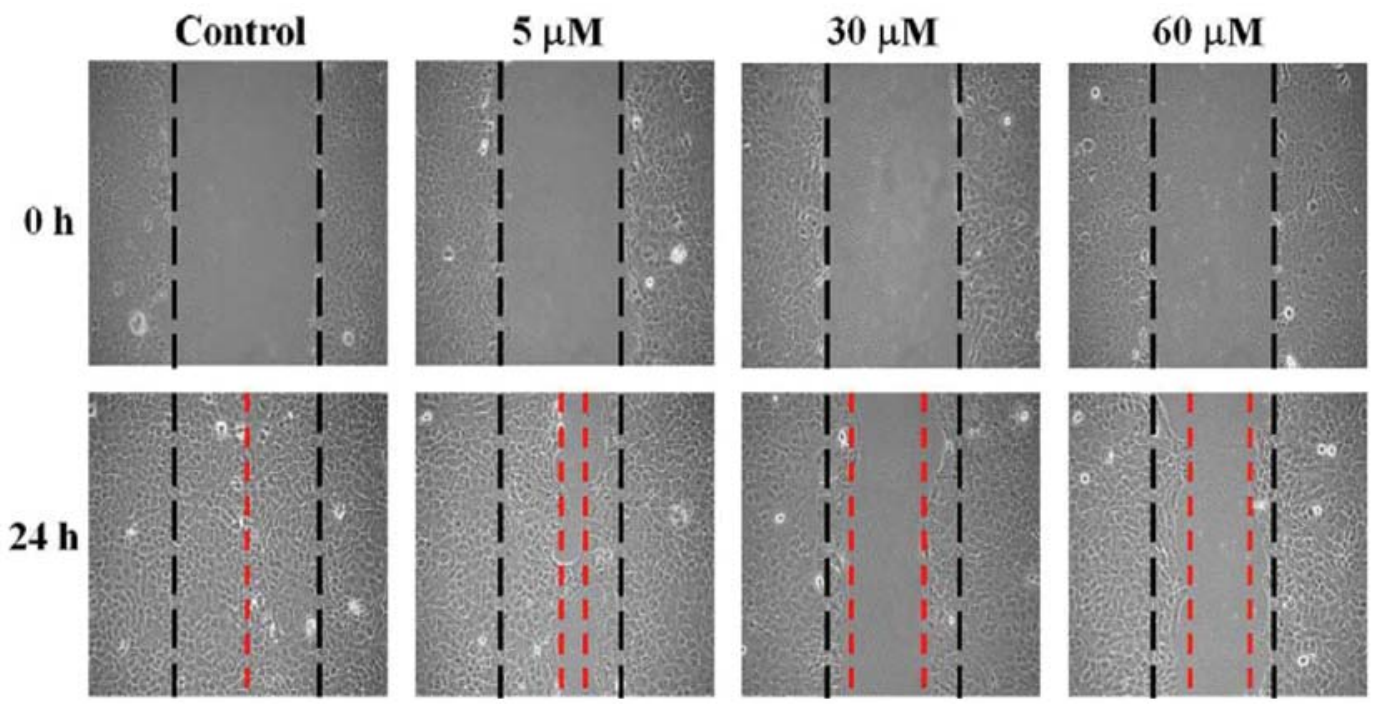

Figure 3. Gallic acid (GA) affects the migration of SCC-4 cell. Cells were kept on the 6-well dish for $24 \mathrm{~h}$ and then a wound was created by a yellow pipette tip to scrape the confluent cell layers. GA $(0,5,30$, and $60 \mu \mathrm{M})$ was individually added to the well and was then incubated for $24 \mathrm{~h}$. Some of the representative images of invading treated and untreated cells are presented.
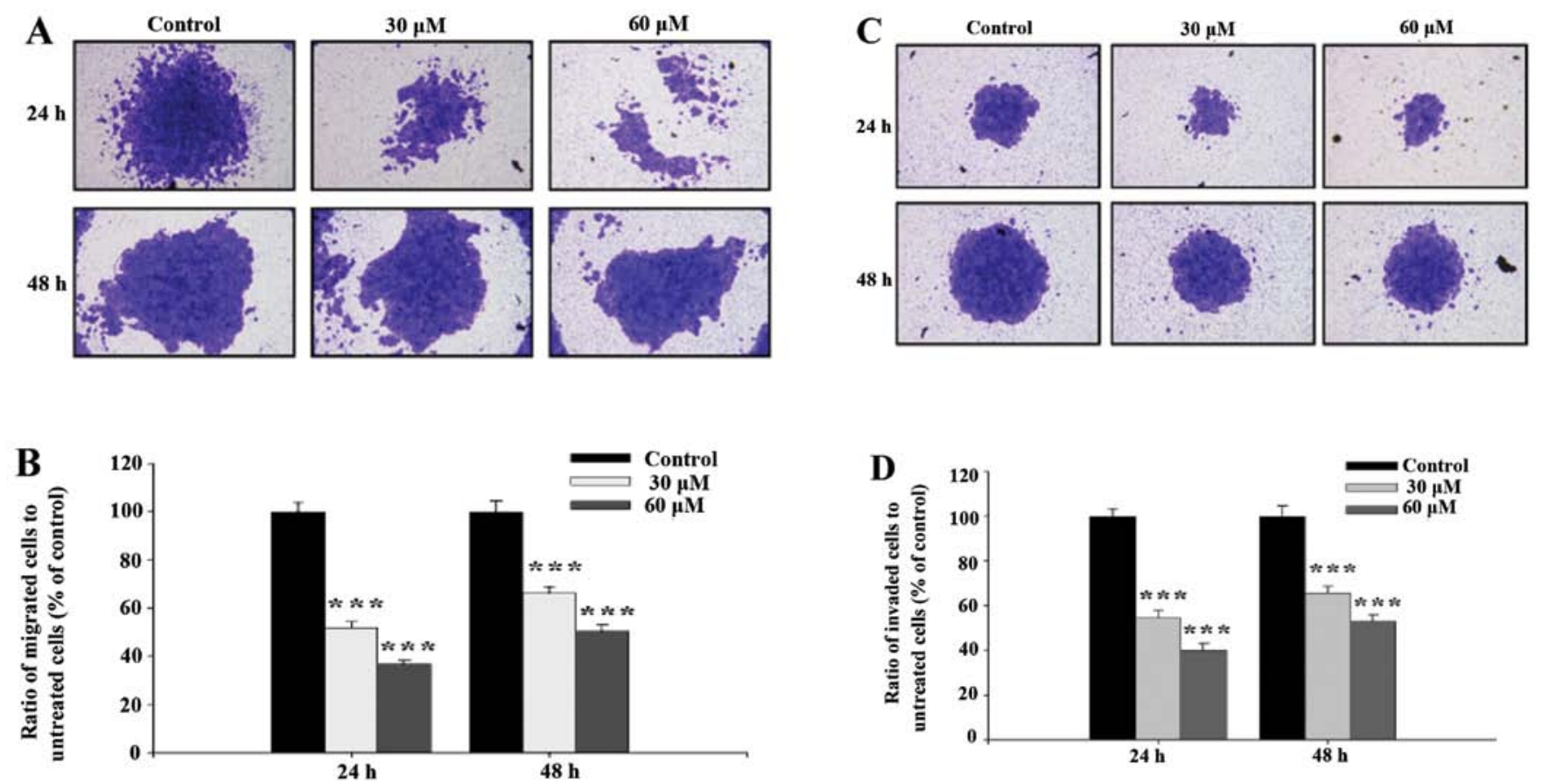

Figure 4. Gallic acid (GA) suppresses the migration and invasion of SCC-4 cells in vitro. Cells $\left(5 \times 10^{4}\right.$ cells/well) were treated with or without GA for $24 \mathrm{~h}$ after cells penetrated through to the lower surface of the filter, without Matrigel for migration examination (A and B), with Matrigel for invasion examination (C and D). They were then stained with crystal violet, examined and images were captured under a light microscope at $\mathrm{x} 200$. Quantification of cells in the lower chambers was performed by counting cells at $\mathrm{x} 200$. Representative columns (mean) from three independent experiments. "P<0.05, significant difference between GA-treated groups and the control as analyzed by Student's t-test.
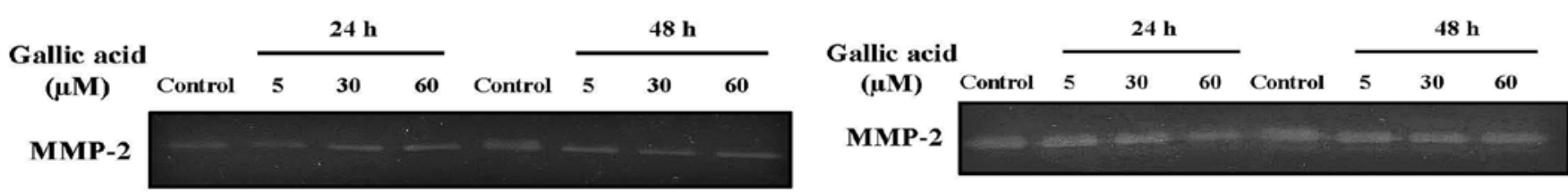

Figure 5. Gallic acid (GA) affects the activities of matrix metalloproteinase (MMP) activities in SAS cells. Cells were treated with or without GA at the final concentration of $0,5,30$ and $60 \mu \mathrm{M}$ and were then harvested and performed by gelatin zymography. Representative zymogram from three independent experiments was used to detect the activity of secreted MMP-2. The different activities of MMP-2 were determined by densitometric analysis and results are expressed as a percentage of the control (100\%). 
A
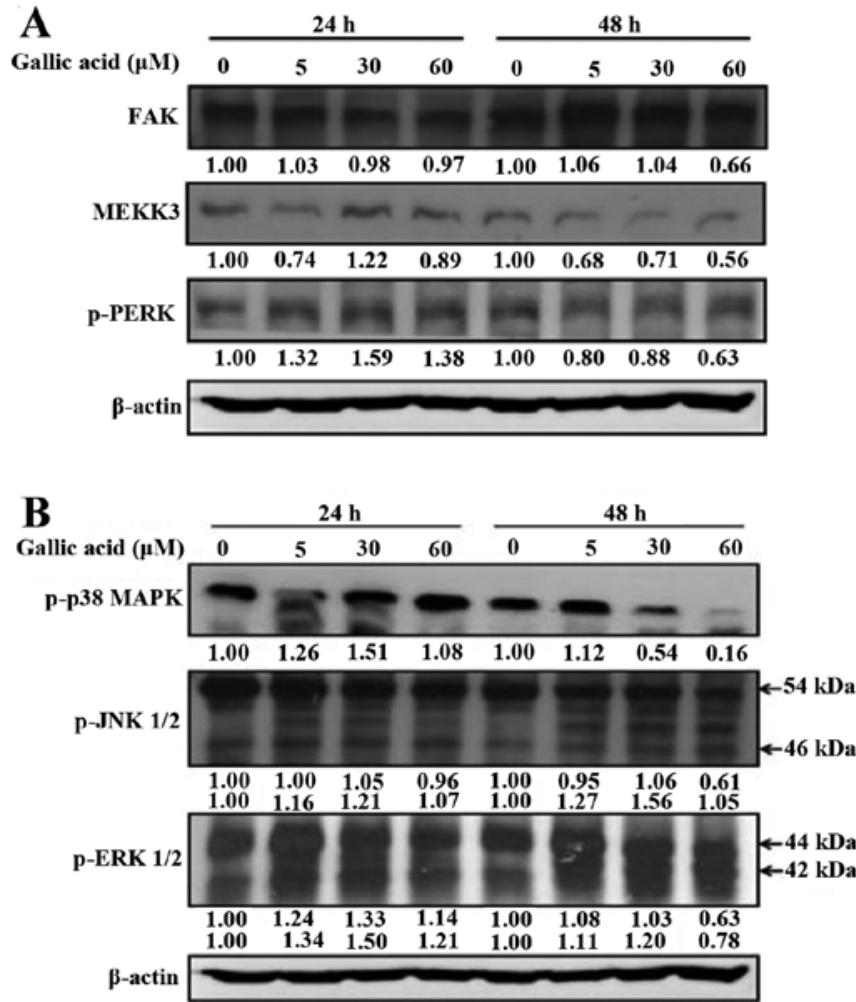

C

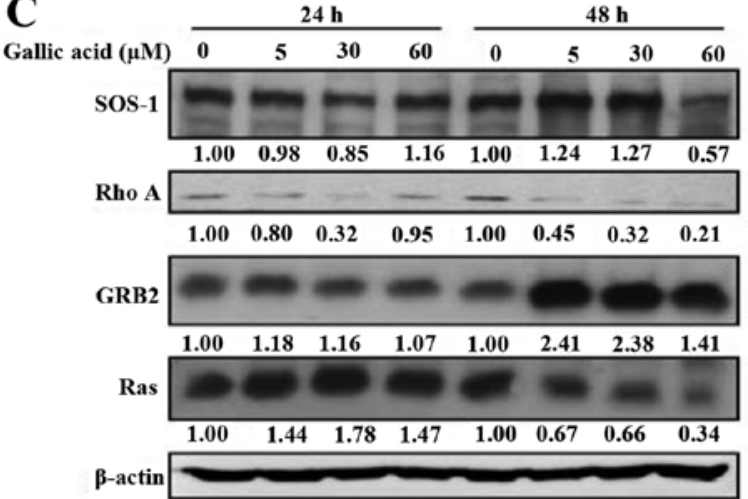

D

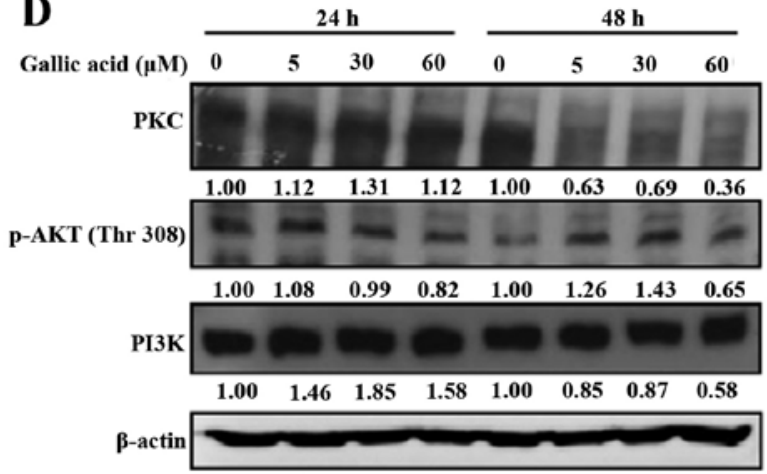

$\mathbf{E}$

Gallic acid $(\mu \mathrm{M})$

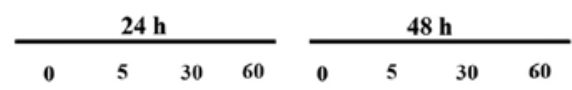

NF-кB p65

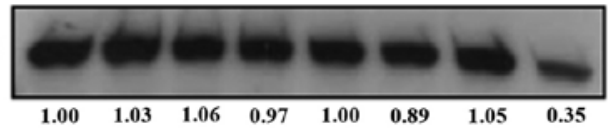

$\beta$-actin

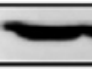

$\mathbf{F}$

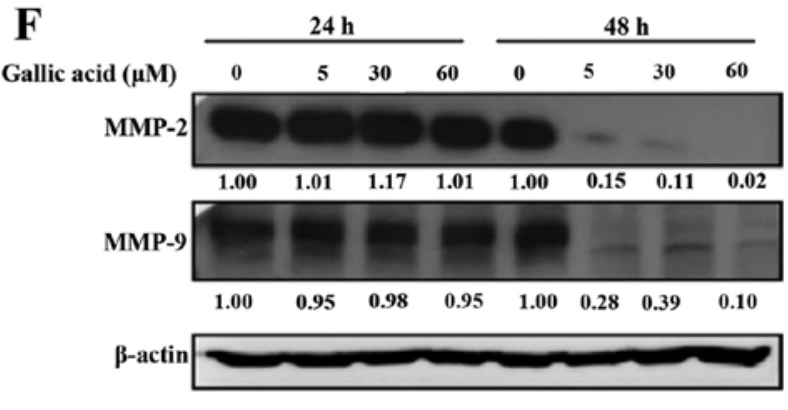

Figure 6. Gallic acid (GA) affects the levels of associated proteins in migration and invasion of SCC- 4 cells. Cells (5x10 ${ }^{4}$ cells/well) were treated with 5, 30 and $60 \mu \mathrm{M}$ of GA for 24 and $48 \mathrm{~h}$ and then cells were collected for the total protein extracted and determined as described in Materials and methods. The levels of FAK, MEKK3, PERK (A); p38, JNK1/2, ERK1/2 (B); SOS1, RhoA, GRB2, Ras (C); PKC, p-AKT(Thr308), PI3K (D); NF-kB p65 (E); MMP-2, MMP-9 (F) expression were estimated by western blotting as described in Materials and methods.

\section{Discussion}

Numerous studies have demonstrated that gallic acid (GA) induces cytotoxic effects through cell cycle arrest and induction of apoptosis in many human cancer cell lines. There are a few reports showing GA inhibited metastasis of cancer cells (15-18). However, the effects of GA on the cell motility of human oral cancer SCC-4 cells have not been examined. We investigated the effects of GA on the migration and invasion of SCC-4 cells in vitro. GA inhibited migration and invasion and these effects were associated with MMP-2 and MMP-9 activity and other specific proteins (NF- $\mathrm{B}$ p 65, RhoA). MMP-2 and MMP-9 play a critical role in cancer cell migration and invasion $(20,21)$ and overexpression of both enzymes increases migration and invasion of cancer cells $(22,23)$. In the present study, we showed that GA markedly inhibited activation status of MMP-2 and MMP-9 using gelatin zymography (Fig. 5). These findings were consistent with our data showing that GA decreased the protein levels of MMP-2 and MMP-9 (Fig. 7F). GA also reduced protein levels of PI-3K and downstream kinases JNK and p-p38 (Fig. 7B), and NF- $\mathrm{kB}$ (Fig. 7E) in SCC-4 cells. These findings are in agreement with another report which found that GA blocked cell migration and invasion which was associated with inhibition of NF- $\mathrm{KB}$ and downregulation of PI3K and AKT signaling (15). It is well documented that NF- $\mathrm{KB}$ acts on downstream proteins such as MMP-2 and MMP-9 $(24,25)$.

GA inhibited the translocation of NF- $\mathrm{KB}$ from the cytosol to the nucleus (Fig. 7A) and significantly reduced protein levels of FAK, MEEK3 and p-PERK in SCC-4 cells. Earlier reports indicated that FAK/Scr was associated with tumor cell migration and invasion $(24,25)$. Activated FAK (Tyr 397)/Src 

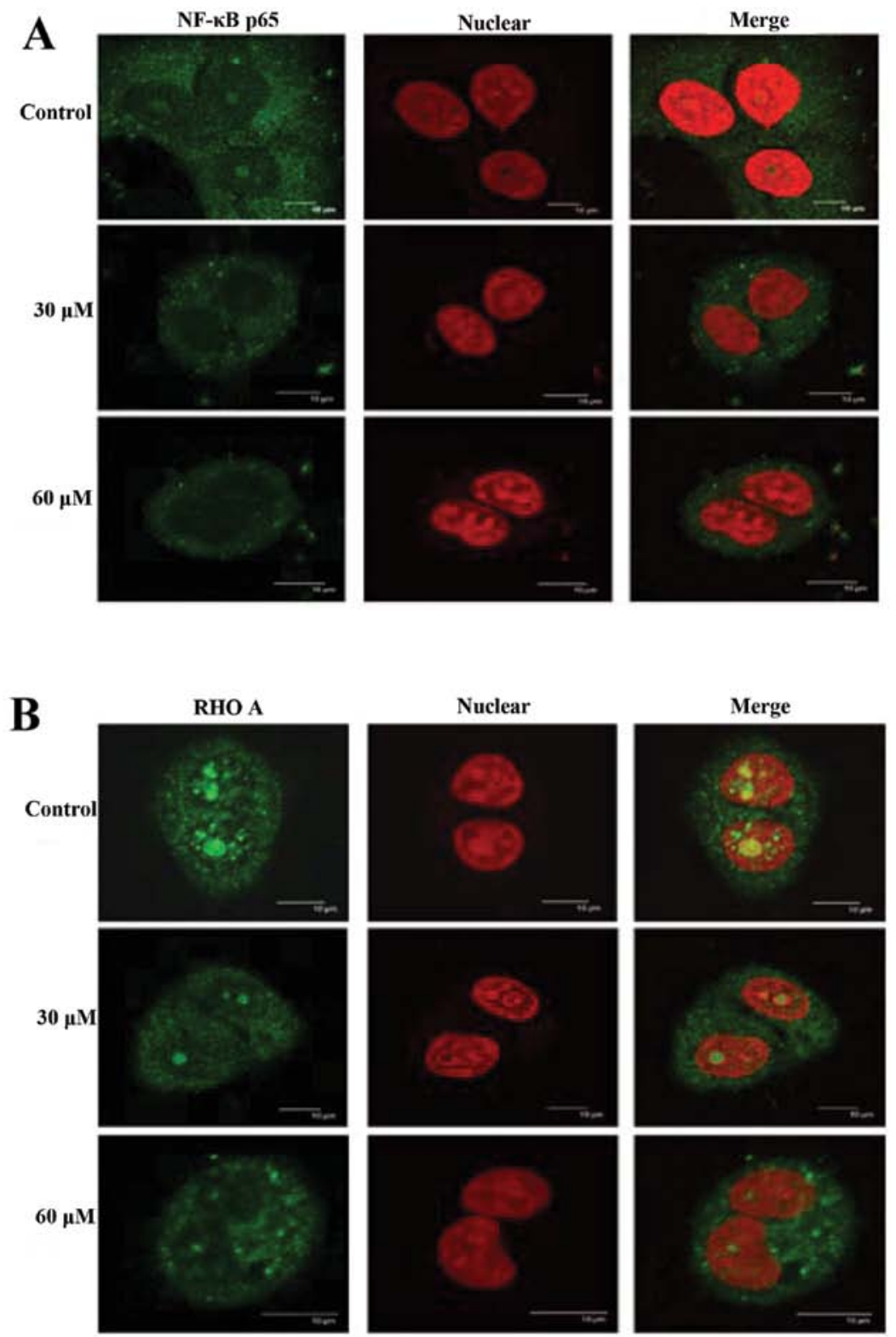

Figure 7. Gallic acid (GA) affects the NF-кB p65 and RhoA translocation in SCC-4 cells. Cells $\left(5 \times 10^{4}\right.$ cells/well) were placed on 6-well chamber slides and were then treated with 30 and $60 \mu \mathrm{M}$ of GA for $24 \mathrm{~h}$. They were then fixed and stained using anti-NF-кB p65 (A), RhoA (B) antibodies (1:100) and stained with a secondary antibody (green fluorescence) followed by nuclear counterstaining with PI (red fluorescence). Photomicrographs were obtained using a Leica TCS SP2 confocal spectral microscope as described in Materials and methods.

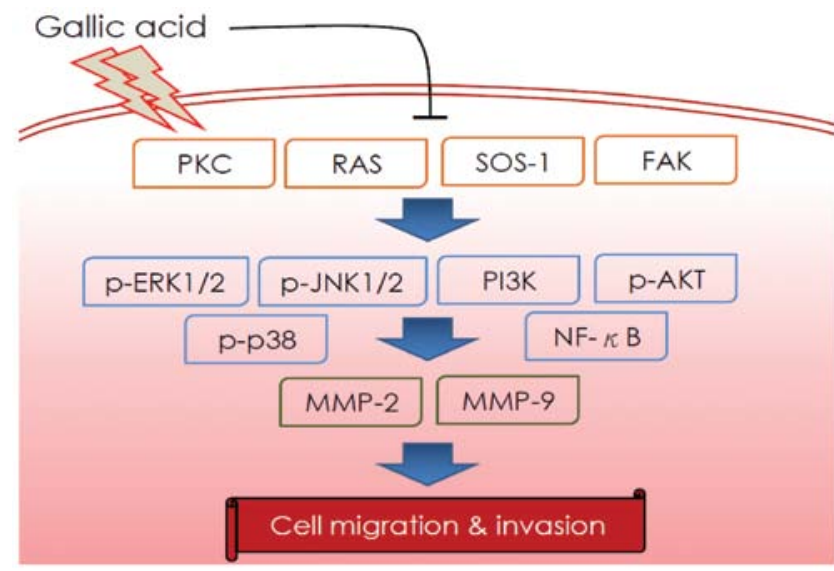

Figure 8. The possible signaling pathways for gallic acid-inhibited cell migration and invasion in SCC-4 human oral cancer cells.
(Tyr 416) may act on PI-3K/AKT and Ras/ERK1/2 cascades impacting signaling $(26,27)$. It was reported that FAK/Src complex allows Src to phosphorylate FAK and then to interact with GRB2 and activation of the Ras-ERK signaling pathway (28).

GA in the present study inhibited the expression of RhoA in SCC- 4 cells. RhoA belongs to the prototype protein of the Rho GTPase superfamily that is associated with cell migration among its many effects (28). Both RhoA and ROCK1 are upregulated in tumors and are predicative of cancer progression, metastasis and poor prognosis $(29,30)$. Inhibition of the RhoA/ROCK1 pathway leads to tumor cell death and reduced metastasis $(31,32)$. The RhoA/ROCK1 pathway may be a promising target for cancer therapy in the future and further investigation is required. 
We found that GA inhibited protein levels of Ras and SOS-1 but increased GRB2 abundance (Fig. 7C) in SCC-4 cells. Numerous studies have demonstrated that Grb2 (33), Ras (34), and PKC $(35,36)$ are involved in cell mobility. GA inhibition of cell migration and invasion of SCC-4 cells may also involve inhibition of SOS-1, Ras and RhoA. As depicted in Fig. 8, we propose that GA inhibition of SCC-4 cell migration and invasion may occur via regulation of PKC, Ras, SOS1, FAK, p-JNK1/2, p-ERK1/2, p-p38, PI3K, p-AKT and NF- $\mathrm{B}$ expression. A major consequence of these effects is inhibition of MMP-2 and MMP-9 activity and protein signaling pathways.

\section{Acknowledgements}

This study was supported by grant DOH99-TD-C-111-005 from Department of Health, Executive Yuan (Taiwan, R.O.C). Experiments and data analysis were performed in part through the use of the Medical Research Core Facilities Center, Office of Research and Development at China Medical University, Taichung, Taiwan, R.O.C.

\section{References}

1. Castro TP and Bussoloti Filho I: Prevalence of human papillomavirus (HPV) in oral cavity and oropharynx. Braz J Otorhinolaryngol 72: 272-282, 2006.

2. Lingen MW, Pinto A, Mendes RA, et al: Genetics/epigenetics of oral premalignancy: current status and future research. Oral Dis 17 (Suppl 1): 7-22, 2011.

3. Scully C and Bagan J: Oral squamous cell carcinoma overview. Oral Oncol 45: 301-308, 2009.

4. Jemal A, Siegel R, Xu J and Ward E: Cancer statistics, 2010. CA Cancer J Clin 60: 277-300, 2010.

5. Inoue M, Suzuki R, Koide T, Sakaguchi N, Ogihara Y and Yabu Y: Antioxidant, gallic acid, induces apoptosis in HL-60RG cells. Biochem Biophys Res Commun 204: 898-904, 1994.

6. You BR, Kim SZ, Kim SH and Park WH: Gallic acid-induced lung cancer cell death is accompanied by ROS increase and glutathione depletion. Mol Cell Biochem 357: 295-303, 2011.

7. Yoshioka K, Kataoka T, Hayashi T, Hasegawa M, Ishi Y and Hibasami H: Induction of apoptosis by gallic acid in human stomach cancer KATO III and colon adenocarcinoma COLO 205 cell lines. Oncol Rep 7: 1221-1223, 2000.

8. Veluri R, Singh RP, Liu Z, Thompson JA, Agarwal R and Agarwal C: Fractionation of grape seed extract and identification of gallic acid as one of the major active constituents causing growth inhibition and apoptotic death of DU145 human prostate carcinoma cells. Carcinogenesis 27: 1445-1453, 2006.

9. Raina K, Rajamanickam S, Deep G, Singh M, Agarwal R and Agarwal C: Chemopreventive effects of oral gallic acid feeding on tumor growth and progression in TRAMP mice. Mol Cancer Ther 7: 1258-1267, 2008 .

10. Locatelli C, Leal PC, Yunes RA, Nunes RJ and CreczynskiPasa TB: Gallic acid ester derivatives induce apoptosis and cell adhesion inhibition in melanoma cells: the relationship between free radical generation, glutathione depletion and cell death. Chem Biol Interact 181: 175-184, 2009.

11. Faried A, Kurnia D, Faried LS, et al: Anticancer effects of gallic acid isolated from Indonesian herbal medicine, Phaleria macrocarpa (Scheff.) Boerl, on human cancer cell lines. Int J Oncol 30: 605-613, 2007.

12. Kang MK, Kang NJ, Jang YJ, Lee KW and Lee HJ: Gallic acid induces neuronal cell death through activation of c-Jun $\mathrm{N}$-terminal kinase and downregulation of Bcl-2. Ann NY Acad Sci 1171: 514-520, 2009.

13. Serrano A, Palacios C, Roy G, et al: Derivatives of gallic acid induce apoptosis in tumoral cell lines and inhibit lymphocyte proliferation. Arch Biochem Biophys 350: 49-54, 1998.

14. Ji BC, Hsu WH, Yang JS, et al: Gallic acid induces apoptosis via caspase-3 and mitochondrion-dependent pathways in vitro and suppresses lung xenograft tumor growth in vivo. J Agric Food Chem 57: 7596-7604, 2009.
15. Ho $\mathrm{HH}$, Chang CS, Ho WC, Liao SY, Wu CH and Wang CJ: Anti-metastasis effects of gallic acid on gastric cancer cells involves inhibition of NF-kappaB activity and downregulation of PI3K/AKT/small GTPase signals. Food Chem Toxicol 48: 2508-2516, 2010.

16. Lo C, Lai TY, Yang JS, et al: Gallic acid inhibits the migration and invasion of A375.S2 human melanoma cells through the inhibition of matrix metalloproteinase- 2 and Ras. Melanoma Res 21: 267-273, 2011

17. Liao CL, Lai KC, Huang AC, et al: Gallic acid inhibits migration and invasion in human osteosarcoma U-2 OS cells through suppressing the matrix metalloproteinase-2/-9, protein kinase $B$ (PKB) and PKC signaling pathways. Food Chem Toxicol 50: $1734-1740,2012$

18. Lai WW, Hsu SC, Chueh FS, et al: Quercetin inhibits migration and invasion of SAS human oral cancer cells through inhibition of NF- $\kappa \mathrm{B}$ and matrix metalloproteinase-2/-9 signaling pathways. Anticancer Res 33: 1941-1950, 2013.

19. Liu KC, Huang AC, Wu PP, et al: Gallic acid suppresses the migration and invasion of PC-3 human prostate cancer cells via inhibition of matrix metalloproteinase-2 and -9 signaling pathways. Oncol Rep 26: 177-184, 2011.

20. Toth M, Sohail A and Fridman R: Assessment of gelatinases (MMP-2 and MMP-9) by gelatin zymography. Methods Mol Biol 878: 121-135, 2012.

21. Sangle NA and Layfield LJ: Telangiectatic osteosarcoma. Arch Pathol Lab Med 136: 572-576, 2012.

22. Shi GZ, Yuan Y, Jiang GJ, et al: PRAF3 induces apoptosis and inhibits migration and invasion in human esophageal squamous cell carcinoma. BMC Cancer 12: 97, 2012.

23. Chen K, Zhang S, Ji Y, et al: Baicalein inhibits the invasion and metastatic capabilities of hepatocellular carcinoma cells via down-regulation of the ERK pathway. PLoS One 8: e72927, 2013.

24. Shen J, Xu L, Owonikoko TK, et al: NNK promotes migration and invasion of lung cancer cells through activation of c-Src/PKCi/FAK loop. Cancer Lett 318: 106-113, 2012.

25. Bianchi-Smiraglia A, Paesante $\mathrm{S}$ and Bakin AV: Integrin $\beta 5$ contributes to the tumorigenic potential of breast cancer cells through the Src-FAK and MEK-ERK signaling pathways. Oncogene 32: 3049-3058, 2013.

26. Mamali I, Tatari MN, Micheva I, Lampropoulou M and Marmaras VJ: Apoptosis in medfly hemocytes is regulated during pupariation through FAK, Src, ERK, PI-3K p85a, and Akt survival signaling. J Cell Biochem 101: 331-347, 2007.

27. Arpaia E, Blaser H, Quintela-Fandino M, et al: The interaction between caveolin-1 and Rho-GTPases promotes metastasis by controlling the expression of alpha5-integrin and the activation of Src, Ras and Erk. Oncogene 31: 884-896, 2012.

28. Bolos V, Gasent JM, Lopez-Tarruella S and Grande E: The dual kinase complex FAK-Src as a promising therapeutic target in cancer. Onco Targets Ther 3: 83-97, 2010.

29. Karlsson R, Pedersen ED, Wang Z and Brakebusch C: Rho GTPase function in tumorigenesis. Biochim Biophys Acta 1796: 91-98, 2009.

30. Li F, Jiang Q, Shi KJ, Luo H, Yang Y and Xu CM: RhoA modulates functional and physical interaction between ROCK1 and Erk1/2 in selenite-induced apoptosis of leukaemia cells. Cell Death Dis 4: e708, 2013.

31. Fromigue O, Haÿ E, Modrowski D, et al: RhoA GTPase inactivation by statins induces osteosarcoma cell apoptosis by inhibiting p42/p44-MAPKs-Bcl-2 signaling independently of BMP-2 and cell differentiation. Cell Death Differ 13: 1845-1856, 2006.

32. Lochhead PA, Wickman G, Mezna M and Olson MF: Activating ROCK1 somatic mutations in human cancer. Oncogene 29: 2591-2598, 2010.

33. Tsai NP and Wei LN: RhoA/ROCK1 signaling regulates stress granule formation and apoptosis. Cell Signal 22: 668-675, 2010.

34. Lee SH, Jeong EG, Nam SW, Lee JY, Yoo NJ and Lee SH: Increased expression of Gab2, a scaffolding adaptor of the tyrosine kinase signalling, in gastric carcinomas. Pathology 39: 326-329, 2007.

35. Zhang J, Anastasiadis PZ, Liu Y, Thompson EA and Fields AP: Protein kinase $\mathrm{C}$ (PKC) betaII induces cell invasion through a Ras/Mek-, PKC iota/Rac 1-dependent signaling pathway. J Biol Chem 279: 22118-22123, 2004

36. Lawler K, Foran E, O'Sullivan G, Long A and Kenny D: Mobility and invasiveness of metastatic esophageal cancer are potentiated by shear stress in a ROCK- and Ras-dependent manner. Am J Physiol Cell Physiol 291: C668-C677, 2006. 